\title{
RECORDAÇÕES AO MAR: A MEMÓRIA DAS EMBARCADAS SOBRE O TRABALHO EM PLATAFORMAS DE PETRÓLEO
}

\author{
Camila Daniel ${ }^{1}$
}

\section{Introdução}

A participação de mulheres no mercado de trabalho brasileiro não é um fenômeno recente. As mulheres têm estado presentes no cenário econômico do país nas mais diversas ocupações, nos mais diversos setores, embora nem sempre notadas e reconhecidas. Na história das mulheres no mercado de trabalho, elas foram amplamente empregadas desde os primeiros anos de industrialização, ainda no século XIX, no período da instalação das primeiras indústrias de substituição de importações. Naquele período, as opções de trabalho para as mulheres eram limitadas por sua classe social: as ex-escravas se dedicavam à prestação de serviços pessoais e domésticos; as mulheres da classe média optavam entre ser professora primária, enfermeira ou parteira; já as mulheres pobres se dirigiram às indústrias (Pena,1981).

Historicamente, as trabalhadoras tiveram sua inserção em atividades econômicas fortemente influenciadas não apenas por sua classe social, mas também pelo seu gênero. Ele é a base para se considerar as mulheres naturalmente mais aptas para determinadas atividades que outras, com base na diferença biológica entre os sexos. No mercado de trabalho, as mulheres têm tradicionalmente ocupado determinadas áreas, tarefas e cargos que se perpetuam como 'guetos' femininos, como por exemplo, na prestação de serviços e tarefas que exigem movimentos minuciosos e delicados. Esta generificação do mundo do trabalho não se detém ao aspecto mais amplo do mercado de trabalho, que torna determinados setores mais "femininos" que outros, mas mesmo um determinado setor ou até mesmo profissão sofre um processo de generificação, ou seja, uma concentração de mulheres em certas atividades, que geralmente são menos prestigiadas e remuneradas. No caso da indústria, a área que tem historicamente sido mais feminina é a da indústria têxtil.

A distinção entre os gêneros no mercado de trabalho também não se limita à maior ou menor inserção de mulheres em determinados setores e profissões. No cotidiano do trabalho, as mulheres também vivem uma experiência marcada pelo princípio diferenciador

\footnotetext{
${ }^{1}$ Universidade Federal Rural do Rio de Janeiro, Brasil.
} 
e hieraquizante, que é o gênero ${ }^{2}$. No ambiente de trabalho, elas estão mais expostas a sanções informais, como brincadeiras, piadas, fofocas e cantadas, que funcionam como estratégias (intencionais ou não) de constrangimento e de resistência contra sua presença. Tal fenômeno faz parte sobretudo da rotina das mulheres que ingressam em profissões tradicionalmente masculinas. Em alguns destes casos, as mulheres adentram locais de trabalho nunca antes ocupados por mulheres, que não dispõem de uma infra-estrutura básica para recebê-las, como, por exemplo, banheiros privativos.

O mundo do trabalho é recortado por uma série de antagonismos e contradições que refutam qualquer possibilidade de neutralidade na sua gestão e organização, por isso, ele também não está neutro diante do gênero, que atua como um classificador fundamental na relação entre as mulheres e o mundo do trabalho remunerado. Se, no início do século XX, as mulheres estiveram restritas a um conjunto de profissões, em meados do século XX e na primeira década do século XXI, encontramos mulheres executando tarefas anteriormente inimagináveis e inaceitáveis para elas. No entanto, esta nova participação da mulher no mundo do trabalho não se dá sem conflito e resistência, que se manifestam de diferentes maneiras, e marcam incisivamente a presença das mulheres no mercado de trabalho como uma experiência de gênero.

Este trabalho tem como objetivo discutir a presença das mulheres no mundo do petróleo, a partir do olhar das próprias mulheres sobre sua experiência neste ramo de trabalho marcadamente masculino. A história do trabalho no mundo do petróleo tem sido uma história de homens, e esta história contribuiu para uma invisibilização da mulher e do seu trabalho como também fundamentais para o desenvolvimento da indústria do petróleo não apenas no passado, mas também no presente. Assim, nós recorreremos ao relato de mulheres que trabalham nesta indústria para refletirmos sobre a relevância do gênero como um princípio classificador dentro do mundo do trabalho.

\section{A inserção no campo e a experiência como (ex)embarcada}

Antes de discutirmos a presença de mulheres nesta área predominantemente masculina, que é a indústria do petróleo, é fundamental compartilhar com os leitores o caminho que me levou a este objeto de pesquisa. Pouquíssimo conhecido pelo público leigo

\footnotetext{
${ }^{2}$ Neste trabalho, nos baseamos na definição de gênero de Scott, 1991.
} 
e acadêmico, o estudo da experiência de mulheres na indústria do petróleo, em geral e em plataformas de petróleo mais especificamente, está intimamente relacionado com minha experiência pessoal, como ex-embarcada.

Meu interesse pelo tema surgiu no período em que cursava a graduação em Ciências Sociais e tive a oportunidade de começar a trabalhar como instrutora de inglês em plataformas de petróleo ${ }^{3}$. Durante o período de Julho de 2005 a Fevereiro de 2007, tive a oportunidade de visitar três plataformas: um navio de produção e duas sondas de perfuração. Antes do primeiro embarque, a diretora do curso teve uma 'conversa' comigo e com as outras instrutoras, dando uma prévia de como seria o cotidiano embarcado. Ela descreveu a rotina diária, o ritmo de aulas, o número esperado de alunos, o rendimento, os relatórios e tudo o que se relacionava aos critérios formais do trabalho. Ela falou também sobre elementos mais gerais, como a comida, os quartos, os banheiros, a prática de exercícios, os espaços para circulação, os meios de comunicação externa. Expôs ainda questões relacionadas a uma 'moralidade' atribuída às professoras, que deveriam se preocupar com o assédio, cantadas, fofocas, evitando relações demasiado próximas com alunos, enfatizando que, por serem minoria num espaço masculino, as mulheres seriam alvos constantes de observações e comentários- quase sempre deletérios.

Os "conselhos" não pararam por aí. A diretora reforçou que os alunos só iriam às aulas se eles tivessem uma boa impressão da professora, se ela os agradasse. Uma "boa" professora teria que conquistar seus alunos e, para isso, ela precisaria ser simpática, atenciosa, uma boa ouvinte, ser cativante. Em outras palavras: a qualificação formal era importante, porém não suficiente. Eram necessárias qualidades pessoais que se relacionam à uma imagem de 'feminino' para que uma professora fizesse um "bom trabalho": afetividade, docilidade, amabilidade.

$\mathrm{O}$ trabalho como professora de Inglês me permitiu ter acesso à vivência na plataforma que resultou na elaboração da minha monografia de conclusão de curso, defendida em Fevereiro de 2006, que se tratou de uma pesquisa etnográfica sobre a

\footnotetext{
${ }^{3}$ A extração de petróleo no Brasil é realizada predominantemente a partir de plataformas marítimas. A dinâmica de trabalho numa plataforma de petróleo exige que o trabalhador passe uma temporada dentro dela, sem contato direto com o mundo exterior. A temporada de trabalho é de geralmente 15 dias. Concluídos os 15 dias de trabalho na plataforma, o trabalhador tem outra temporada de folga, de também 15 dias. Quando estão na plataforma, os trabalhadores tem uma rotina diária de 12 horas de trabalho, mas permanecem na plataforma quando não estão trabalhando. Assim, a plataforma é um espaço que concentra trabalho e casa. Os homens e mulheres que trabalham nessa dinâmica são chamados de "embarcados" e "embarcadas".
} 
dinâmica das relações sociais na plataforma. Através da convivência e do diálogo com homens e mulheres embarcados, pude concluir que o trabalho que os indivíduos executam é o elemento principal de inserção nas relações sociais na plataforma. As tarefas que eles desenvolvem funcionam como um mapa de acesso aos espaços, horários e relações: é partir da função que exercem que os indivíduos são designados aos quartos, tem uma equipe de trabalho delimitada e horários definidos. Dentro do já limitado espaço da plataforma, os indivíduos ficam restritos ao convívio daqueles que fazem parte de sua equipe de trabalho ou possuem horários de trabalho e não-trabalho parecidos com o seu. O confinamento borra as fronteiras entre o trabalho e o não-trabalho, uma vez que os indivíduos permanecem na plataforma mesmo depois de terminada sua jornada de trabalho e continuam encontrando as mesmas pessoas com quem conviveu naquele mesmo período.

Além disso, percebi que 'ser homem' e 'ser mulher' são aspectos importantes para compreender as relações entre os embarcados, a atividade que executam e sua posição na hierarquia social da plataforma, apresentando-se transversalmente nas esferas da vida social na plataforma. A definição do que seria "masculino" e "feminino" entre os embarcados se corporifica numa delimitação do espaço físico, dos contatos cotidianos, dos comportamentos e expectativas sociais atribuídas aos indivíduos. Das mulheres, esperavase um comportamento dócil, simpático, afetuoso, carinhoso; dos homens, virilidade, vigor e força. Mulheres que não apresentassem características "femininas" e homens características "masculinas" eram encarados com estranheza. Esta estranheza poderia ser expressa por olhares, boatos e fofocas. A questão de gênero se mostrou fundamental na plataforma, local onde casa e trabalho estão sempre se confundindo de um modo específico, apresentando um modus operandi que lhe é próprio.

\section{As mulheres no mundo do petróleo: as pioneiras}

Apesar de ainda serem minoria diante de um grande número de homens, as mulheres nunca estiveram ausentes do mundo petróleo no Brasil. Algumas mulheres iniciaram seu trabalho em plataformas de petróleo ao mesmo tempo em que os primeiros poços em subsolo marítimo foram encontrados, no final dos anos de 1970. No entanto, antes mesmo de embarcarem, as mulheres já estavam presentes na indústria petrolífera de 
outra forma, também fundamental para a exploração nacional de petróleo: nas pesquisas geológicas em busca de poços.

O primeiro poço em subsolo marítimo foi datado por uma geóloga, Marília da Silva Paes Regali, que conta a dificuldade que enfrentou para entrar na Petrobras. Na faculdade, ela sempre ouvia dos professores e de todos os outros alunos que ela deveria entrar na empresa. No entanto, quando tentou se inscrever descobriu que para uma mulher seria mais difícil:

Quando uma comissão da Petrobras fez o primeiro contato na USP, o chefe do grupo nos disse sem meias palavras: 'Para mulher não tem nada'. Eu e a Brigit [...] ficamos desoladas. Só com a entrada do dr. Lang no circuito é que fui chamada. Logo ao ser admitida, fui enviada à Região de Produção da Bahia, que não tinha quarto separado para mulheres nem banheiro feminino.

(Cadernos Petrobras, Março de 2006 - grifo nosso).

Em 1960, Marília foi então finalmente admitida na Petrobras. É importante notar que neste período, a indústria do petróleo estava sob monopólio da Petrobras, por isso, a empresa aparece como um ator de suma relevância na inserção das mulheres no mundo do petróleo. Outra observação que precisamos ressaltar é que o fato de Marília ter sido contratada depois da primeira recusa, não significou uma automática aceitação e acomodação de mulheres nesta indústria tão marcadamente masculina. Isto fica nítido na declaração de Marília, que expõe que no lugar onde trabalhou não tinha quarto nem banheiro femininos.

Outro exemplo de que a mulher ainda estava longe de ser de fato aceita na indústria do petróleo é relatado por outra geóloga, Maria Rita Caetano Chang. Décadas depois da contratação de Marília, as mulheres continuaram enfrentando resistência para ingressar na indústria petrolífera. Maria Rita comenta que na sua experiência de trabalho enfrentou o mesmo desestímulo que Marília quando, em 1974, tentou se candidatar à Petrobras:

Já ao final de 1974, prestes a graduar-me, a Petrobras [...] enviou a Rio Claro dois agenciadores de candidatos a trabalhar em diferentes áreas da pesquisa e exploração petrolífera brasileira. Fui, novamente, 'barrada no baile': 'A Petrobras não está convocando mulheres!' [...] até 1976, a empresa tinha apenas uma ou duas mulheres, que atuavam em seus laboratórios.

(Jornal da Unesp, Abril de 2003- gripo nosso). 
Diante de tal negativa, Maria Rita e um grupo de geólogas recém-formadas iniciaram um movimento contra as restrições impostas às mulheres em diversas áreas da Geologia, principalmente na Petrobras e nas empresas de mineração. Lombardi (2006) mostra que ainda hoje, na Engenharia, as áreas de Minas, incluídas a prospecção de petróleo, Metalurgia e Mecânica, são de mais difícil acesso para as mulheres. As razões enumeradas por engenheiros e engenheiras para tal fenômeno se centram nas condições de trabalho propiciadas neste ramo da engenharia: "ambientes de trabalho agressivos e insalubres, processos de trabalho "pesados" em fundições e indústrias metalúrgicas e mecânicas, trabalho realizado em pontos longínquos ou muito distantes das zonas urbanas como é o caso das prospecções de minérios" (Lombardi, 2006: 14).

Assim, estaria implícita a ideia de que as mulheres, mesmo que tenham a formação acadêmica, elas não possuiriam as outras habilidades que são tacitamente exigidas para cada tipo de atividade dentro da Engenharia. Ao que tudo indica, estas habilidades se apoiam numa divisão do trabalho em "trabalho de homem" e "trabalho de mulher", mostrando que o gênero interfere no trabalho. As declarações de Maria Rita e Marília indicam que esta noção generificada do trabalho dentro de uma determinada área acadêmica não está restrita à Engenharia, mas também parece vigorar na Geologia, na época de Marília e Maria Rita. Por isso, elas não eram consideradas como trabalhadoras em potencial para ingressar no mundo do petróleo.

A experiência de Maria Rita, 14 anos depois da integração de Marília ao quadro de funcionários da Petrobras sugere que, o fato de já existir uma mulher contratada pela empresa não significou uma automática abertura para o ingresso de mulheres nas áreas técnicas. As mulheres continuaram sendo preteridas quando se candidatavam a ingressar no mundo do petróleo. Entretanto, ainda que de maneira restrita, as mulheres participaram dos primeiros embarques nas plataformas na costa brasileira e grande parte desta participação feminina esteve associada à pressão que as mulheres exerceram para que não fossem impedidas de participar destas novas oportunidades de trabalho que se descortinavam.

\section{A mulher e seu lugar no mundo do petróleo}

A experiência vivida e contada pelas geólogas suscita uma reflexão sobre o lugar que a mulher tem ocupado no espaço, na memória e no imaginário do mundo do trabalho 
petrolífero. Apesar dos depoimentos de Marília e Maria Rita, que evidenciam a disputa que se travou entre as mulheres e os dirigentes da empresa onde desejavam ingressar, pouco ou nada se sabe sobre a presença das mulheres na indústria petrolífera como um todo, e no mundo das plataformas de petróleo mais especificamente.

Uma grande dificuldade que encontramos para analisar a história da presença das mulheres no mundo do petróleo é a escassez de dados sobre o assunto. Por isso, uma estratégia fundamental para tentarmos conhecer a presença das mulheres neste ramo marcadamente masculino foi recorrer a depoimentos de mulheres que trabalham nesta indústria. Elas são fundamentais como fontes sobre o passado e para evitar que toda experiência que as mulheres viveram no mundo do petróleo- desde os anos 60- se perca e caia no esquecimento.

Nesta pesquisa, entrevistamos um total de 15 mulheres trabalhadoras em plataformas de petróleo. Todas elas atuam nesta dinâmica de trabalho, que exige delas um afastamento do mundo exterior por uma temporada - de geralmente 14 dias - para desenvolverem suas atividades profissionais no interior das plataformas. Quando estão embarcadas, o contato com o mundo exterior se dá apenas através de instrumentos de comunicação como telefone, revistas, jornais, televisão e internet (Daniel, 2009).

A presença de mulheres em plataformas tem sido notada por diferentes autores que se propuseram a estudar o trabalhador embarcado. Pessanha (1994) conta que durante os 10 dias que permaneceu embarcado encontrou diversas mulheres trabalhando nas plataformas, inclusive uma em cargo de chefia. Naquele período, o autor calculou que existiam 10 mulheres como operadoras na Bacia de Campos. Nas cinco plataformas onde embarcou, ele pessoalmente encontrou 6 mulheres: três funcionárias da Petrobras e três terceirizadas. Martins (2006), na sua pesquisa sobre as repercussões do confinamento em trabalhadores de plataformas de petróleo, encontrou na plataforma onde concentrou sua análise um total de 6 mulheres dentre os 336 profissionais embarcados. Embora notando a presença de mulheres em plataformas de petróleo, nenhum deles inclui nem mesmo uma mulher em suas análises. 


\section{Poucas em número, muitas em significado: por que estudar as mulheres embarcadas?}

Durante minha pesquisa de mestrado, de março de 2007 a junho de 2009, uma pergunta me foi feita por todos aqueles que descobriram que o meu tema de pesquisa era a percepção das mulheres embarcadas em plataformas sobre a relação entre trabalho remunerado e vida familiar. A pergunta era sempre seguida por um comentário: "Por que estudar mulheres embarcadas? São tão poucas!"’. Sim. Se compararmos numericamente a presença de homens e de mulheres que trabalham em plataformas de petróleo elas são poucas sim. No entanto, a razão que me levou a me dedicar às mulheres embarcadas justamente não foi uma questão de número. A escassez de dados (estatísticos, mas também qualitativos) sobre a presença de mulheres nas plataformas parece contribuir para que elas continuem excluídas das pesquisas sobre o ramo.

Rodrigues (2001) aponta a construção de uma cultura particular de trabalho nas unidades de perfuração brasileiras, aos moldes americanos, caracterizada pelo uso de tecnologia inovadora, a proibição de consumo de bebidas alcoólicas, o confinamento dos trabalhadores e a ausência de mulheres. O autor afirma no seu estudo que nas UPMs ${ }^{4}$ brasileiras mais $95 \%$ dos trabalhadores é do sexo masculino; o contato com as mulheres é escasso e quando ocorre aparece como um elemento novo, perturbador e causador de estresse. A caracterização da mulher como um "elemento perturbador" parece indicar uma particularidade da vivência das embarcadas na plataforma, uma vez que o espaço da plataforma e as relações sociais nela desenvolvidas não se mostram receptivos ao ingresso de mulheres.

As mulheres em plataformas podem ser poucas em número, mas elas são muitas em significado. Numa plataforma, por maior que seja o número de homens no seu interior, se uma mulher está presente ela já ocupará um espaço de extrema relevância na vida social dos embarcados. Uma mulher apenas é capaz de fazer com que todos os embarcados reflitam sobre o comportamento socialmente esperado de uma mulher e, também de um homem nestas condições de reclusão e isolamento. Por isso, a presença de uma mulher é tão significativa exatamente porque dela será esperado um comportamento distinto daquele convencionado para os homens. Assim, ser uma mulher embarcada traz implícito a ideia de que uma mulher já tem a capacidade de representar a mulher e ofeminino, como um todo, o

\footnotetext{
${ }^{4}$ Unidade de Perfuração Marítima.
} 
que dá um sentido todo particular à convivência entre homens e mulheres embarcados. Esta convivência - sempre relacional - está submersa numa teia de significados ancorado no gênero, ou seja, na noção de que a diferença sexual produz naturalmente diferenças em comportamento, habilidades e formas de pensar de homens e mulheres. No entanto, longe de serem diferenças naturais, estas diferenças são socialmente (re)produzidas e (res)significadas. Por isso, no caso das mulheres embarcadas, número e significado não necessariamente andam juntos: uma mulher numa plataforma já é suficiente para suscitar maneiras de pensar e organizar o cotidiano na plataforma.

O pequeno número de mulheres trabalhando em plataformas de petróleo em comparação ao número de homens e a caracterização do trabalho em plataformas como um 'trabalho pesado' e masculino traz consigo também algumas consequências. O argumento de que as mulheres são tão poucas - o que traz implícito que, por isso, não seria necessário estudar tal tema -, tem contribuído para que tais mulheres sejam invisibilizadas nas categorias "petroleiros", "trabalhadores offshore" ou "embarcados", classificações rotineiramente carregadas de uma conotação masculina e vinculada ao trabalhador da Petrobras.

\section{Como se sente uma mulher embarcada}

A invisibilização das mulheres não é a única consequência provocada pela masculinização das análises sobre os trabalhadores embarcados. Não incluir as mulheres em pesquisas, estudos e estatísticas sobre o trabalho no mundo do petróleo representa uma desvalorização da experiência das mulheres, que vivem uma situação de trabalho tão peculiar e que deixa explícita as contradições que estruturam as relações de gênero no mundo do trabalho. Uma das embarcadas que entrevistei expressou como ela sente sendo uma mulher que trabalha numa plataforma de petróleo, neste espaço fechado e masculino. À pergunta: "você acha que os homens e mulheres na plataforma são iguais?", ela respondeu:

Não. Muita gente acha assim: 'ah, são todos iguais, porque todos vão trabalhar'. Não! ...o homem vai olhar a mulher como olha qualquer mulher na rua: se é bonita, se é feia, se tem corpão, se é simpática. Se a mulher é séria, vão dizer que a mulher é metida. Se a mulher é uma pessoa cativante, já acham que a mulher é oferecida... É difícil! Eu me 
vejo como uma mulher batalhadora, porque ficar 15 anos embarcando, ouvindo vários tipos de insinuações, eu sou vencedora. E.

A embarcada E. toca num ponto sensível para as mulheres embarcadas, que torna sua experiência de trabalho muito específica em comparação à experiência dos homens: o que ela chama de insinuações. As mulheres embarcadas estão sujeitas a formas veladas de assédio, que, por muitas vezes sutis que são, não são tão fáceis de serem explicadas, questionadas e combatidas. Quando as insinuações tomam a forma de cantadas abertas e explícitas, as mulheres vivem o constrangimento de não saberem exatamente como responder a tais investidas, principalmente quando elas ocupam um lugar pouco valorizado na hierarquia social da plataforma.

M. R. embarca há mais de 10 anos como taifeira ${ }^{5}$. Ela conta que nos seus primeiros anos como embarcada era muito comum receber cantadas de seus superiores:

Era uma época em que a mulher era muito mais vista como.. assim... um petisco ${ }^{6} \ldots \mathrm{Eu}$ falei com um homem que tentou me jogar nessa, mas eu bati de frente com ele. Eu falei com ele que mandasse a mãe dele levar chazinho no quarto, que eu não era paga pra levar chazinho não. Que meu serviço é fazer a limpeza... Aí, ele tentou me queimar, mas aí a firma ${ }^{7}$ não deixou. Ele passou um tempão de mal e começou a usar as outras meninas, e parou de mexer comigo.

A fala de M. R. é muito significativa por relatar o processo muito comum de assédio o qual as mulheres estão sujeitas, principalmente as taifeiras. No primeiro momento, o homem faz uma insinuação - geralmente com olhares e gestos -, de que tem algum interesse sexual na mulher. Em seguida, as insinuações tomam forma de cantadas expressas verbalmente, como que um convite para sair no desembarque; uma proposta de visitar o camarote dele fora do horário de expediente ou, no caso de M. R. solicitar um serviço que não faz parte de suas das atribuições. M. R. indica que "levar um chazinho" representa algo além de apenas servir um chá. $\mathrm{O}$ tom de revolta na fala de $\mathrm{M}$. R. nos faz crer que o "chazinho" seria um pretexto para que este homem ficasse sozinho no seu camarote com M.R. Ela, percebendo as intenções do seu superior, se negou veementemente servi-lo. O homem em questão, não satisfeito com a negativa de M.R., tentou aplicar sobre ela uma

\footnotetext{
${ }^{5}$ As taifeiras são trabalhadoras responsáveis pela limpeza e arrumação dos quartos, escritórios e áreas de convivência da plataforma. A presença de mulheres como taifeiras é rotineira.

${ }^{6}$ Aperitivo, como algo para os homens desfrutar.

${ }^{7}$ Empresa.
} 
retaliação, o que M. R. chama de queimar. No mundo embarcado, queimar significa fazer queixa sobre uma pessoa para seus superiores e convencê-los a aplicar uma sanção contra a pessoa queimada, que geralmente é mudar a pessoa de plataforma, trocar de funções ou até mesmo, em casos extremos, a demissão.

Muitas mulheres, conscientes deste ritual de assédio se sentem intimidadas quando recebem cantadas dos seus colegas da plataforma, sobretudo quando estes homens fazem parte da chefia. Eles são os que concentram o poder de queimar oficialmente uma mulher que não queira ceder às suas investidas. O poder que eles detém faz com que eles se sintam autorizados a interferir pessoalmente na carreira de trabalhadores e trabalhadoras das empresas terceirizadas. Neste caso, há uma assimetria entre empresa contratante x empresas terceirizadas e essa assimetria entre as empresas é refletida numa assimetria de poder entre os empregados destas empresas.

No caso das taifeiras, elas são funcionárias terceirizadas, o que significa que elas e suas empresas fornecem serviços para uma segunda empresa, a quem eles prestam contas. Quando as insinuações se dão entre homens das empresas contratantes sobre mulheres de empresas contratadas (terceirizadas), elas são tomadas pelo temor que sua recusa à investida do homem seja revertida num desentendimento entre as empresas e, por isso, ela teme que ela e sua empresa sofram conseqüências negativas oriundas de sua recusa à cantada. Assim como M. R., a taifeira P., que embarca também há mais de 10 anos, conta que na sua trajetória como embarcada tem sido muito comum ser assediada por seus colegas de plataforma, principalmente por seus superiores:

Quando chefe vem me cantar, eu fico sem saber o que fazer. Não posso dá logo um fora, porque eu não sei o que o chefe pode fazer. Ele tem poder, pode querer me queimar, me tirar da empresa. Se for peão, eu dou logo um fora. Mas chefe, é mais complicado. Então, eu falo: "ah, não dá, não quero, sou casada". Mas, o homem acha que a gente ta fazendo doce, fazendo charme. Que é só insistir, que a gente vai ceder.

P. expressa como se sente quando recebe cantadas de um chefe. Embora não sabendo o que fazer em resposta às cantadas, ela tem total consciência de que ele, como chefe, pode aplicar sanções que a prejudique no trabalho, ou seja, ele poderia queimá-la. P. sabe que, se ela rejeitasse abertamente as investidas de um chefe ela estaria sujeita a retaliações que poderiam até mesmo colocar seu emprego em risco. Por isso, ela optava por 
uma postura menos enfática que a de M.R. Ao invés de dar "logo um fora", P. optava por uma saída mais "diplomática", com mais sutileza e delicadeza. Se o homem em questão fosse um "peão", P. não precisava de uma postura mais delicada, porque, ela sabia que estes homens não poderiam impor sobre ela nenhuma sanção oficial ${ }^{8}$. Nesta relação, tanto P. e como o "peão" estão em desvantagem diante da "chefia". No entanto, se as cantadas vierem da "chefia", P. considera que um "fora" explícito e aberto poderia lhe causar problemas maiores, por isso sua opção era de não aceitar a cantada, mas de uma maneira camuflada. No entanto, esta saída mais branda é interpretada pelo chefe como "fazer doce". Isto significa que a via diplomática muitas vezes é interpretada pelo homem como uma estratégia feminina para que ele insista mais intensamente nas cantadas, até que um dia a mulher ceda.

Para P., não são apenas as cantadas que tornam sua rotina na plataforma bem diferente da rotina de um homem embarcado. Na própria dinâmica de trabalho ela recebe um tratamento diferenciado, carregado pela marca de gênero. Quando descreve sua rotina de trabalho, que incluiu limpar os camarotes, P. revela que se sente constrangida por, muitas vezes, os embarcados não saírem do camarote para ela limpar:

Tem cara que não sai do quarto pra gente limpar... Fica lá, vendo televisão... Aí, eu limpo com eles lá dentro mesmo. E é muito chato! Pra arrumar a cama, a gente tem que se abaixar, abrir as pernas, ficar com a bunda pra cima... E eles lá, fingindo que tão vendo televisão, mas olhando pra gente.

Os relatos das embarcadas deixam latentes as formas de constrangimentos as quais as mulheres estão sujeitas dentro da plataforma, principalmente - mas não exclusivamente quando inseridas numa ocupação de pouco prestígio social. Estas mulheres enfrentam um dupla desvantagem: a de ser mulher num espaço masculino, mas também de ocupar um lugar subalterno na hierarquia social da plataforma. Esta combinação gera uma condição aviltante para as mulheres que vivem ao mesmo tempo uma dominação de gênero e de classe.

\footnotetext{
${ }^{8}$ Embora os "peões" não ocupem posições de poder que lhe dêem condições de aplicar sanções oficiais contra as mulheres que lhe "dão um fora", eles podem aplicar outras tipos de sanções não-oficiais, como fofocas, comentários deletérios e olhares que constranjam as mulheres. Estas sanções, oficiais ou não, explicitam a relação de poder que é estabelecida dos homens sobre as mulheres.
} 
Um ponto que não pode deixar de ser considerado quando analisamos as falas de E., M. R. e P. é que elas trabalham embarcadas há mais de 10 anos. Os acontecimentos relatados pelas embarcadas aconteceram nos seus primeiros anos de embarque, ainda nos anos 90. Elas comentam que hoje até recebem cantadas, mas percebem uma mudança significativa na maneira como a mulher é tratada pelos seus colegas de trabalho dentro da plataforma do período quando começaram a embarcar para os tempos atuais. E. conta que, na época que era taifeira, sofreu severamente numa plataforma em que foram espalhados boatos sobre sua conduta sexual. Estas fofocas fizeram com que ela sofresse um mal-estar tão profundo que ela achou que estava depressão. Estas embarcadas avaliam que hoje as mulheres são mais respeitadas, e menos quando são cantadas, estas são menos ofensivas que as do passado.

M.R., P. e E. acreditam que no passado eram comuns dois fenômenos: de um lado, os homens pouco respeitavam as mulheres; de outro, muitas mulheres usavam o trabalho em plataformas como trampolim para "encontrar um marido". Elas consideram que estes dois fenômenos estão interligados, porque, o fato de existir mulheres nas plataformas que cedem às cantadas e se envolvem sexualmente com homens embarcados seria uma razão para que os homens não respeitassem as mulheres e acreditassem que todas as mulheres estariam disponíveis para encontros sexuais.

Nos anos mais recentes, elas contam que percebem uma mudança em ambos os lados: hoje, mais do que nunca, as mulheres embarcadas estão mais concentradas em suas carreiras e por isso cedem menos às cantadas; e por isso, os homens estão reconhecendo as mulheres como profissionais e não apenas como uma possível parceira sexual. Ou seja, M. R., P. e E. acreditam para uma mulher ser respeitada é uma questão de como ela se comporta diante dos homens. Se uma mulher não é respeitada significa que ela não adota um comportamento digno de respeito. Por isso, as mulheres seriam as principais culpadas pelo tratamento que recebem dos seus colegas de trabalho. O curioso desta análise é que todas elas já se sentiram desrespeitadas na plataforma, e quando isso aconteceu, elas ficaram indignadas e não acharam justo não receberem o respeito o qual se julgam digna.

No entanto, as embarcadas entrevistadas consideram que os homens hoje respeitam mais as mulheres não só pela mudança do comportamento das mulheres, mas também 
porque hoje existem sanções formais que podem ser aplicadas sobre homens autores de assédio sexual, quando a mulher denuncia.

A reflexão sobre o passado e o presente nas plataformas de petróleo realizado por E., M. R. e P. sobre a mudança de tratamento das mulheres pode ser comparado com a fala das mulheres que começaram a trabalhar embarcada mais recentemente, já no anos 2000. É interessante notar que entre estas embarcadas, nenhuma declara explicitamente sofrer alguma forma de discriminação por parte de seus colegas de trabalho. Elas dizem que na sua experiência pessoal na plataforma não sentem que são tratadas de uma maneira desigual, em relação aos homens.

No entanto, algumas das entrevistadas apresentam um discurso dúbio: elas afirmam que não se sentem discriminadas e que as mulheres se adaptam bem à vida embarcada, mas contam casos em que se sentiram constrangidas diante dos embarcados, seja por causa de piadas, que elas consideraram machistas, seja por conta de cantadas ou fofocas. Um caso muito emblemático é o da assistente administrativo K. Ela conta que tem um ótimo relacionamento com seus colegas de plataforma e que tem amizade com todos eles, com exceção de um. Este homem se declarou apaixonado por K., que é casada e não tem nenhum interesse em se relacionar com ele. Ele, indignado com a recusa, começou a persegui-la no trabalho, criticar sua atuação profissional para seus superiores e fazer constantes ameaças contra ela. Mesmo assim, K. julga este como um fato isolado provocado por homem psicologicamente desequilibrado.

Então, eu tenho tido muito atrito com essa pessoa a bordo. Muito mesmo. A ponto dele me xingar, me tratar mal. De não fazer espaço no corredor pra eu passar, quando a gente vem de frente um pro outro. Tá uma situação bem complicada! É uma pessoa que não tem a mínima noção de educação, de profissionalismo...

A radio-operadora G. assume uma posição crítica diante da relação de homens e mulheres na plataforma. No momento da entrevista ela trabalhava embarcada há 3 anos e considerava que era mais difícil o homem aceitar conviver com mulheres na plataforma do que o contrário. Sobre a relação das mulheres com os homens embarcados, ela declara:

Eu acho que a mulher encara com mais naturalidade. Eu não vejo nada muito estranho na relação das mulheres a bordo com os homens. 
Mas, sobre a relação dos homens com as mulheres, ela apresenta um outro ponto de vista:

\begin{abstract}
O homem geralmente ainda se sente superior à mulher; e particularmente, acho que a mulher embarcada ainda sofre muito preconceito. Eu acho que o preconceito não é explícito, mas é assim um preconceito ainda sombreado pela questão do tipo 'aqui não é seu lugar', 'aqui é lugar para homens', 'mulher tem que ficar em casa lavando roupa'. Eu vejo isso muito claramente no momento em que as pessoas socializam mais que é o momento da comida, quando todo mundo tá no refeitório. Então, você que tem grupos... tem homens que não inserem a mulher na sua conversa... E às vezes sempre as brincadeiras, pejorativas de um modo geral, envolve o nome de uma mulher... Como se ela fosse mulher, não um ser pensante.
\end{abstract}

Assim, observamos que as mulheres que trabalham embarcadas há mais de 10 anos falam mais abertamente sobre a discriminação contra as mulheres nas plataformas, confidenciando suas próprias experiências de constrangimento e mal-estar. Já há mulheres que embarcam por cerca de 5 anos, declaram que não há um tratamento desigual entre homens e mulheres na plataforma, mas, algumas delas, comentam situações em que sentiram incomodadas pela forma como foram tratadas pelos homens de sua plataforma. $\mathrm{O}$ depoimento das mulheres mais antigas nas plataformas, comparado com as que embarcam num período mais recente nos ajuda a refletir sobre a relação entre homens e mulheres na plataforma, numa perspectiva histórica.

As regulações mais rigorosas que se esforçam a punir qualquer tipo de discriminação no trabalho podem explicar o fato de não se presenciarem formas de constrangimento e discriminação explícitas contra mulheres neste período mais recente. No entanto, nós também podemos refletir se estas regulações tem sido também eficiente para evitar os constrangimentos e a discriminação sutil, as formas veladas de discriminação, que se expressam por olhares, fofocas e outras maneiras de desprestigiar a mulher e seu trabalho.

\title{
Considerações Finais
}

Neste artigo, discutimos a presença das mulheres no mundo do petróleo, tentando recorrer a uma perspectiva histórica. Incluir a experiência das mulheres na história do petróleo tem o primeiro objetivo de evitar a 'história única', que conta o passado tendo como referência apenas a experiência do homem, que assume então o lugar de história 
oficial. $\mathrm{O}$ fato da presença feminina ser numericamente menor que a presença masculina no mundo do petróleo escamoteia a relevância das mulheres como atores sociais que interferem na realidade, principalmente quando ingressam em espaços masculinos.

Quando as mulheres são esquecidas, é esquecido também que o mundo do trabalho não está cego diante das diferenças de gênero. A experiência das embarcadas deixa evidente que o mundo do trabalho, mesmo na sua forma embarcado - neste caráter tão excepcional -, é estruturado pela noção de que os homens e mulheres são diferentes por natureza e, por isso, eles não estariam aptos para executarem as mesmas tarefas. Tudo isso porque eles estariam naturalmente predispostos a executarem tarefas diferentes, com base na diferença de seus sexos. No entanto, reconhecer a especificidade da experiência das mulheres embarcadas significa reconhecer que as relações entre homens e mulheres na plataforma não estão isentas ao gênero.

A análise feita por G. nos indica que ela assume uma posição crítica diante da sua experiência como embarcada, reconhecendo a existência de formas de discriminações que se camuflam e assumem formas veladas de preconceito. A falta de G, também nos leva a refletir sobre o significado que a presença de mulheres nas plataformas assume para o homem, que sempre pensou o espaço embarcado como exclusivamente masculino. Levando em consideração que o gênero se configura como um classificador social que é sempre relacional, G. nos alerta para o fato de pensar as relações de gênero na plataforma como um meio para entender não só como as mulheres se sentem diante do comportamento dos homens, mas também entender como os homens se sentem diante do comportamento das mulheres. Assim, evitaremos pensar numa relação entre vítima e algoz, mas reconheceremos o caráter dinâmico que o gênero assume no mundo do trabalho.

\section{Referências}

DANIEL, Camila. Mulheres embarcadas: gênero, família e trabalho na percepção de mulheres em espaços masculinos. Dissertação (mestrado em Ciências Sociais), PPCIS/UERJ. Rio de Janeiro: UERJ, 2009.

. "Do lar ao mar: a experiência de trabalho das taifeiras". In: $32^{\circ}$ Encontro da ANPOCS. Caxambu: mimeo, 2008. 
. A Ilha dos Embarcados: um estudo sobre uma plataforma de petróleo, (Trabalho de conclusão de graduação em Ciências Sociais), CCH/UENF. Campos dos Goytacazes: UENF, 2006.

GEERTZ, Clifford. "Estar aqui: a antropologia e o cenário da escrita". In: Obras e Vidas. $2^{\text {a }}$ ed. Rio de Janeiro: Ed. UFRJ, 2005.

Janeiro: Ed. UFRJ, 2005. . "Estar lá: de quem é a vida, afinal?". In: Obras e Vidas. 2aed. Rio de

JORNAL DA UNESP. Ano 176, abril de 2003. Disponível em: http://www.unesp.br/aci/jornal/176/encarte2.htm. Acessado em setembro de 2008.

LOMBARDI, Maria R. "Engenheiras brasileiras: inserção e limites de gênero no campo profissional". In: Cadernos de Pesquisa, v. 36, n. 127. São Paulo: Fundação Carlos Chagas, 2006.

MARTINS, Salvador Marcos Ribeiro. O trabalho offshore: um estudo sobre as repercussões do confinamento nos trabalhadores das plataformas de petróleo na Bacia de Campos. Dissertação (mestrado em Políticas Sociais), CCH/ UENF. Campos dos Goytacazes: UENF, 2006.

MORAES PESSANHA, Roberto. O trabalho off shore: inovação tecnológica, organização do trabalho e qualificação do operador de produção na Bacia de Campos-RJ. Dissertação (mestrado em Engenharia de Produção), COPPE/ UFRJ. Rio de Janeiro: UFRJ, 1994.

PONTES, Ana P. C. "Isso não é coisa de homem": trabalhadoras numa profissão tradicionalmente masculina. Dissertação (mestrado em Sociologia e Antropologia). IFCS/UFRJ. Rio de Janeiro: UFRJ, 2002.

PENA, Maria V. J. Mulheres e Trabalhadoras: presença feminina na constituição do sistema fabril. Rio de Janeiro: Paz e Terra, 1981.

PETROBRAS. Revista Petrobras. Ano 14, n.135. Rio de Janeiro: Ipsis Gráfica e Editora, 2008.

PETROBRAS. As Mulheres e a Petrobras. Rio de Janeiro: Ed. Petrobrás, 2007.

RODRIGUES, Valdo. Relações de trabalho em unidades de perfuração marítima - estudo de caso com ênfase em trabalho em turnos. Dissertação (mestrado em Administração). Alfenas: UNIFENAS, 2001.

SCOTT, Joan W. A Cidadã Paradoxal: as feministas francesas e os direitos do homem. Florianópolis: Mulheres, 2002.

SCOTT, Joan. Gênero, uma categoria útil para análise histórica. Recife: mimeo, 1991.

Recebido em: 03/04/2012

Aprovado em: 19/06/2012 